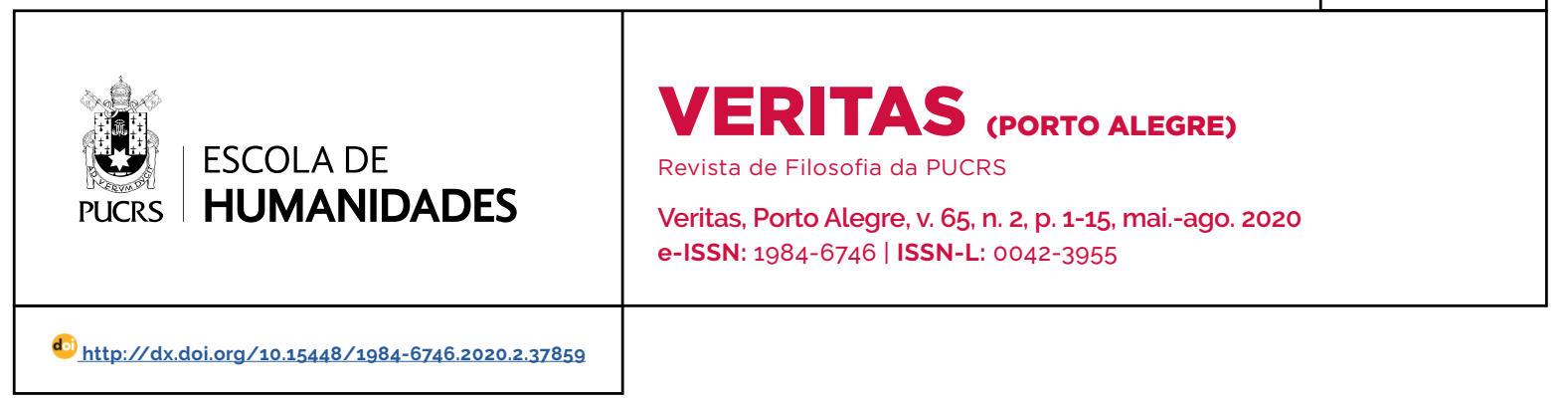

SEÇÃO: ESTÉTICA

\title{
A nova estética de R. Musil e os "estados de agregação" da alma e do intelecto
}

\author{
R. Musil's Modern Aesthetics in the Light of the "Aggregation States" of the Soul and the Intellect \\ La nueva estética de R. Musil y los "estados de agregación" del alma y del intelecto
}

\author{
Kathrin Rosenfield ${ }^{1}$ \\ orcid.org/0000-0002-0061-3208 \\ kathrinrosen@gmail.com
}

Recebido em: 28 abr. 2020. Aprovado em: 12 mai. 2020. Publicado em: 28 jul. 2020.

\section{(c) (1)}

Artigo está licenciado sob forma de uma licença Creative Commons Atribuição 4.0 Internacional.
Resumo: Esse artigo aborda o entrelaçamento inextricável entre o pensamento racional, os sentimentos e a concepção estética do romancista Robert Musil. Mostra como a compreensão da história das ciências e a familiaridade com os métodos do trabalho científico foram transpostas para os dominios humanisticos, desafiando a polarização típica da época que privilegiava dicotomias opondo racionalidade vs. sentimento, precisão matemática vs. intuição artística. Musil ao contrário mostra como o rigor do pensamento matemático e a capacidade de distinguir as sensações e ordenar os sentimentos beneficia a sensibilidade e todo o dominio ético e estético. Palavras-chave: Musil. Ensaio vs. sistema filosófico. Narrativa moderna. Romance.

Abstract: This article deals with R. Musils ways of intertwining rational thinking, feelings and the aesthetics in both the authors essays and novels. It shows how his deep understanding of the history of science and his familiarity with the methods of scientific work were transposed to the humanistic domains, challenging the polarization typical of the time that privileged dichotomies opposing rationality vs. feeling, mathematical precision vs. artistic intuition. Musil on the contrary shows how the rigor of mathematical thought is linked to the increasing ability to distinguish more precisely sensations and emotions. Pursuing this endeavor in accordance with the modern rational achievements would help to create a better order in the psychological and moral domain, as well as benefit the whole ethical and aesthetic domain. Keywords: Musil. Essay vs. philosophical system. Modern narrative. Novel.

Resumen: Este artículo aborda el entrelazamiento inextricable entre el pensamiento racional, los sentimientos y la concepción estética del romancista Robert Musil. Muestra cómo la comprensión de la historia de la ciencia y la familiaridad con los métodos del trabajo científico fueron transpuestas a los dominios humanistas, desafiando la polarización típica de la época que favorecia las dicotomías opuestas a la racionalidad versus el sentimiento, la precisión matemática versus la intuición artística. Musil en cambio muestra cómo el rigor del pensamiento matemático y la capacidad de distinguir sensaciones y ordenar sentimientos beneficia la sensibilidad y todo el dominio ético y estético.

Palabras-clave: Musil. Ensayo vs. sistema filosófico. Narrativa moderna. Novela.

\section{Introdução}

Partindo da formulação inusitada "estados de agregação da moral" que Musil anotou certa vez no seu diário, examinaremos em três passos os elos de mútua dependência que o autor estabelece entre, de um lado o refinamento milenar do pensamento racional e de todo o progresso da matemática e das ciências e, de outro, a progressão de concepções mais sutis dos sentimentos e da psicologia, da moral e da sociedade humanas. 
Musil tinha razão em não reconhecer, em pessoa alguma, distinção superior à sua; entre aqueles que eram considerados escritores não havia em Viena, e talvez nem em todo o domínio da língua alemã, um único que tivesse sua importância. ${ }^{2}$

Em 1910, quatro anos depois de publicar 0 Jovem Törless, Musil terminou, enfim, sua difícil segunda obra (as novelas Uniões). É um periodo de incertezas, primeiro porque Musil duvida que suas novelas teriam o sucesso do primeiro romance, segundo, porque se preocupa com sua carreira de escritor. Nesse momento de crise ainda sorrateira, ele começa a anotar ideias sobre as relações da moral com a arte. É um assunto antigo que acompanha a reflexão estética desde Platão e Aristóteles, mas ele recebe na reflexão de Musil um novo horizonte que conecta a moral e a estética com o conhecimento científico.

O autor começa com a seguinte pergunta, um tanto criptica à primeira vista: "I. Uma pergunta meramente moral: os estados de agregação da moral". 3 Estados de agregação é um termo técnico da física que designa as mudanças de estado e de consistência de uma substância (líquido, sólido, gasoso). A metáfora e a formulação assinalam nas entrelinhas que as ciências exatas desenvolveram técnicas de observação que faltam no domínio da ética e da estética. O cientista sabe que precisa de coletas de dados e de relações quantificáveis para poder descrever de modo preciso as condições sob as quais ocorrem tais mudanças. Artistas e filósofos morais, ao contrário, se contentam em operar com noções vetustas e vagas de uma tradição humanística milenar. Onde as técnicas científicas apuram a observação e descobrem inúmeros fenômenos e relações, a poesia e a moral operam com ferramentas que ficam muito aquém do potencial de inspiração imaginativo dos métodos científicos. Esses últimos, por mais que tenham sido denunciados como frios e mecânicos, teriam ao menos a virtude de livrar a imaginação e a poesia dos seus excessos ora fantasiosos, ora convencionais. Musil inverte o olhar habitual, salienta o potencial poético e inovador do pensamento racional que deveria inspirar artistas e filósofos - se esses desejarem sair dos redundantes motivos e temas de seus cânones.

Os escritores deveriam apropriar-se das técnicas científicas e começar a adotar no seu domínio a disciplina metódica do físico, químico ou biólogo por exemplo, quando registra e compara a cor e o cheiro da água, as diferentes densidades do vapor, a morfologia das gotículas compondo as neblinas ou as nuvens até sua precipitação em forma orvatho ou de chuvas, as diversas formas dos cristais de neve, etc. Inspirado pelo melhor dos escritos ensaísticos de Goethe e de Hume, Musil gostaria de introduzir um pouco do rigor das ciências exatas no pensamento de assuntos morais e espirituais, a fim de liberá-los da miséria dos estereótipos vagos.

Ele continua o esboço com as seguintes ponderações:
II. Toda grande arte é ética/moral. Mas como se fosse em estado gasoso e avessa ao sólido e fixo. Exemplos. Disso se segue que arte não pode ser avaliada com moral sólida, senão não há arte. E daí resulta que não precisamos sem- pre acreditar no que artistas dizem. Eles são estimuladores, não pensadores sistemáticos
III. No entanto, há uma grande conclusão éti- $\mathrm{ca} / \mathrm{moral}$ que decorre disso tudo: escutar e esperar. Não ter preconceitos. Não querer triangular o caos.
IV. Uma questão estética: a corporificação da moral. ${ }^{4}$

A anotação lembra as admoestações de Goethe sobre a importância do rigor científico, ${ }^{5}$ inclusive para a arte. $O$ cientista se obriga a registrar com vagar e disciplina, a descrever com precisão matemática as qualidades e relações do fenômeno, a "observar e ordenar" antes da formulação de hipóteses e ideias; ${ }^{6}$ o método o protege da aceitação das semiverdades que irritam Musil na crítica de arte e nas teorias dos

\footnotetext{
CANETTI, Elias. Jogo dos Olhos. São Paulo: Companhia das Letras, 2010. p. 175.

Cf. MUSIL, Robert. Kleine Prosa und Schriften. Rowohlt. Reinbeck bei Hamburg, 1978. p. 1304.

4 MUSIL, 1978, p. 1304.

5 GOETHE, J. W. von. Sämtliche Werke, 40 v. Deutscher Klassiker. Verlag: Frankfurt, 1989. Cf. em particular os escritos científicos e metodológicos de Goethe sobre morfologia (v. 24) e as ciências naturais em geral (v. 25).

6 Ibid. Bd. 25 Schriften zur allgemeinen Naturlehre, p. 137.
} 
próprios artistas, que, muitas vezes, operam com ideais e dicotomias que ficam aquém das sutis observações científicas ou do realismo prático que o autor aprecia nos autores anglo-saxões. Um remédio para a pobreza imaginativa das convenções seria o estilo que Musil encontra por exemplo no tratado ensaístico de David Hume de 1739, que lhe fornece o seguinte leitmotiv:

Disputas [sobre assuntos éticos] se multiplicam como se tudo estivesse incerto; e essas disputas são processadas com o maior calor, como se tudo estivesse certo. Em todo esse alvoroço não é a razão que ganha, mas a eloquência; e o proselitista da mais extravagante hipótese não corre risco algum, se tiver o ardil adequado para apresentá-la em cores favoráveis. A vitória não será ganha pelas lanças e espadas dos guerreiros; mas pelos tambores, as fanfarras e os músicos do exército?

Durante os seus primeiros anos de escritor, Musil topava sempre de novo com a estéril oscilação entre o gosto convencional - ora na forma daquele mecânico pater noster estético de citações e palavras aladas dos clássicos, ora na dos juizos sutis dos estetas a par das últimas novidades francesas, impressionistas ou expressionista - uma oscilação de perspectivas (nacionalista ou cosmopolita) por sua vez convencional e plasmada na estéril dicotomia opondo a Cultura da Alemanha e da Áustria (Europa Central) à Civilização liberal e politizada da França e da Inglaterra (Europa Ocidental). "Cultura x Civilização [Kultur x Zivilisation] foi a fórmula que iria acirrar cada vez mais os impasses ideológicos sob o pretexto da análise da crise da cultura. ${ }^{8}$. Ela aprofundou o apego dos contemporâneos de Musil a uma cultura venerada como um fetiche, no orgulho dos austriacos e alemães pelos feitos geniais dos grandes poetas e pensadores do classicismo de Weimar e do Idealismo alemão, e no menosprezo pelos méritos das outras tradições culturais, mesmo que essas fossem mais complexas e diversificadas que a relativamente recente Kultur germânica.
O escritor de O Homem sem qualidades adivinhava no fundo desse apego à cultura uma tenaz resistência à modernidade e à racionalidade esclarecida da era científica. As denúncias contra as hipertrofias da razão, do cálculo e da mecanização de todas as relações escondiam mal o anacrônico idealismo sentimental que fugia dos desafios contemporâneos, colocando ênfase exacerbada nas virtudes da alma, do espírito e da emoção. Mais do que das aberrações da razão, Musil desconfiava desses desvarios da sensibilidade hipertrófica e manteve cuidadosa distância da atmosfera esotérica, neomística e elitista que pairava em torno de figuras como Stefan George, Klages, Maeterlinck e tantos outros guias espirituais, que contribuiram, apesar de boas intenções e da excelência dos seus trabalhos, para o mal da época, descrito nos seguintes termos pelo filósofo Karl Mannheim:

\begin{abstract}
Em toda parte, [pessoas] à espera dos profetas e lideres. $O$ ar carregado com pequenos e grandes profetas. Um jura pela biblia de R. Steiner, o outro pela de O. Spengler. Há ainda Blüher, Kayserling e centros que prometem a reforma de culturas inteiras; há os apóstolos de Wyneken e os de George. O que reina é uma inaudita disposição de homens e mulheres à espera de uma redenção qualquer, o que predomina é um certo vazio, um sentimento de falta que não se consegue preencher. ${ }^{9}$
\end{abstract}

Mesmo a críticos que respeita, como Hermann Bahr, Musil recomenda às vezes mais disciplina racional e uma linguagem mais precisa que evite analogias entre a ciência matematizada do século XX e os principios de Goethe e Haeckel - imprecisões que terminam por legitimar (involuntariamente) deslizes intelectuais que terminam promovendo certos adágios banais ou os cliché de reformadores ultraconservadores como Johannes Müller ou Keyserling ${ }^{10}$ e de seus movimentos (reacionários) para o "Cuidado de Vida Íntima", para a liberação do espírito e a expansão das almas.

A fuga para as concepções orgânicas do século XVIII não traz remédios para as caóticas especia-

\footnotetext{
7 Musil cita essa passagem de Hume nos seus diários. Cf. MUSIL, R. Tagebücher, 2 v. Rowohlt, Reinbeck bei Hamburg, 1976, p. 664, v. 1 Cf. HUME, David. Treatise of Human Nature Being an Attempt to Introduce the Experimental Method of Reasoning into Moral Subjects. Oxford: Clarendon Press, 1978.

8 Por exemplo, na polêmica de Thomas Mann contra a concepção engajada, política da literatura de seu irmão Heinrich, ver MANN, T. Betrachtungen eines Unpolitischen. Berlin: Insel Verlag, 1922 [1918], em particular o capitulo Der Zivilisationsliterat, p. 44-73.

9 MANNHEIM, 1921, p. 81 apud WOLF, Christian. Kakanien als Gesellschaftskonstruktion, Robert Musils Sozioanalyse des 20. Jahrhunderts. Viena: Böhlau, 2012. p. 557.

10 Cf. a crítica dirigida a H. Bahr no ensaio "Sobre Livros de Ensaios" (MUSIL, 1978, p. 1450-1457.
} 
lizações científicas modernas, mas serve como pretexto para o antimodernismo conservador que condena o intelecto, o parlamento e a ideia da reorganização da sociedade de massas. Por mais que Musil aprecie os poetas e pensadores do Classicismo de Weimar, ele insiste que não são eles que terão as soluções para a crise da cultura contemporânea, nem ideias de como remediar os impasses da ordem social e todo o sistema de valores das sociedades modernas. O que é preciso é compreender a lógica do trabalho científico. A humanidade avançou graças às ciências que criaram novas categorias profissionais e toda uma nova concepção do trabalho coletivo. São essas estruturas protodemocráticas que precisam ser exploradas para criar melhores condições sociais no mundo das tecnologias industriais sustentadas por massas de trabalhadores, associações e grupos de interesses que pouco combinam com as hierarquias herdadas de outros tempos.

Os ensaios de Musil exortam artistas e criticos a desinflar seus sonhos de grandes sentimentos, e a aprender dos cientistas métodos mais sóbrios e exatos que trariam benefícios também no âmbito da alma e do espírito. Eis o que Musil recomenda no seu "Perfil de um Programa" de 1912:

Toda ousadia da alma está hoje nas ciências exatas. Aprenderemos não de Goethe, Hebbel, Hölderlin, mas de Mach, Lorenz, Einstein, Minkowski, von Couturat, Russell, Peano [...]

No programa desta arte, os principios de uma obra poderiam ser:

Ousadia matemática, dissolver a alma em elementos, ilimitada permutação destes elementos, tudo se relaciona com tudo e pode ser construido a partir dai. Esta construção não prova que uma coisa consiste nisto ou naquilo, mas: é com isto que ela se relaciona. Também na apresentação teremos, portanto, apenas séries de dados coletados. A suposta psicologia é, na verdade, um pensamento ético mais solto e livre - alguns dirão que isto é arte amoral; mesmo assim, só esta arte é moral. ${ }^{11}$
Combinando os métodos das ciências exatas com as novas técnicas experimentais da teoria da Gestalt e as leituras de Nietzsche e Hume, Musil se transforma em "monsieur le vivisecteur"12 - um título que agrada ao jovem escritor pelas suas conotações transgressoras e quase sacrílegas que pairava sobre os anatomistas do Renascimento. Suas anotações e seus ensaios observam o ser humano com a lente de um físico ou biólogo examinando uma substância, despojando as tradicionais ideias do caráter de seus atributos metafísicos, como a essência moral (boa ou má) ou o núcleo espiritual da natureza humana. Esse olhar científico já prepara nas anotações e nos fragmentos em torno de 1900 a visão radicalmente moderna do ser humano que mais tarde encontrará a forma do "homem sem qualidades". O jovem ensaista registra em toda parte uma avassaladora maleabilidade que beira a ausência radical do "caráter" e aproxima o humano de uma massa gelatinosa, sempre pronta a se dissolver e reacomodar em novas formas. Ele destaca como a coisa mais fundamental do ser humano essa prontidão de reconfigurar-se de modo surpreendente, assim que se oferecem moldes para acolher e sustentar o plasma humano sem estrutura própria. Musil não é o primeiro a desenvolver essa ideia; suas observações desdobram o conceito do "Eu irredimivel" de Mach, ${ }^{13}$ transformando-o no teorema da "falta de estrutura e forma próprias" Gestaltlosigkeit,, ${ }^{14}$ que representa o esboço para a figura da "falta de qualidades definidas" (Eigenschaftslosigkeit) do seu protagonista, o homem sem qualidades.

A sobriedade científica é a prescrição musiliana contra o humanismo inflado da época e toda a retórica dos grandes sentimentos, grandes guias, gênios ou heróis - de Goethe a Rembrandt ou Frederico II. Ele procura distinguir os elãs postiços

\footnotetext{
11 MUSIL, 1978, p. 1318.
}

12 MUSIL, 1976. p. 1. v. I.

13 Cf. MACH, Ernst. Die Analyse der Empfindungen. Jena, G. Fischer, 1902, desconstruiu o "Eu" em conjuntos de sensações (elementos) que podem ser reconfigurados à vontade. Além das sugestões precoces à respeito da falta de forma própria do ser humano, Musil desenvolve seu teorema da Gestaltlosigkeit nos ensaios A Nação como ideal e como Realidade (Die Nation als Ideal und als Wirklichkeit [1921] in Kleine Prosa und Schriften [MUSIL, 1978, p. 1059-1075]); Das hilflose Europa oder Reise vom Hundertsten ins Tausendste (1922) (MUSIL, 1978, p. 1075-1094) (A Europa Desamparada ou Viagem das considerações infinitesimais); ou Der deutsche Mensch als Symptom (1923) (MUSIL, 1978, p. 1353-1400) ("O Alemão Como Sintoma) fornecem análises mais sistemáticas da ideia da natureza humana como massa plástica ou amorfa à espera de moldes externos (MUSIL, 1978, p. 1368, 1081).

14 Cf. também o capítulo Gestaltlosigkeit, de Norbert Wolf (WOLF, N.; NÜBEL, B., 2016, p. 712-719). 
(meramente retóricos) dos sentimentos autênticos e sua justa expressão artística. Os esboços "Sobre a Moral" e "Sobre a Quantificabilidade da Moral"15 mostram que essa desconstrução não prega a impossibilidade universal de atribuir valores e de julgar. Ao contrário, Musil invoca a matemática moderna cujas equações operam com dados e incógnitas tão complexos quanto as vaguezas da arte e do sentimento, mas não se permitem o desleixo das formulações retóricas que costuma reinar no mundo da arte e da moral.

Podemos dispensar a polêmica sobre se todo o edifício dos nossos valores morais talvez dependa da sua aplicação aos casos particulares, a tal ponto que a estrutura das suas regras e leis gerais se parece com uma peneira cuja utilidade depende tanto da trama firme quanto dos buracos; basta dizer que há questões na vida tão dependentes das circunstâncias individuais e das condições emocionais que elas não admitem resoluções gerais. Portanto, o problema não é a oposição do indivíduo à ordem moral do mundo, o que, em última análise, sempre redunda em um preguiçoso compromisso entre simpatias e preconceitos - o problema é a própria ordem moral num caso que não pode mais ser decidido de modo universal e obrigatório. E esse problema é polissêmico, tem inúmeras soluções, nenhuma delas é a certa, mas cada uma precisa estar certa; o que há de reflexivo na arte encontra nisso seu limite e sua fundamentação. ${ }^{16}$

Em outras palavras, Musil não é favorável ao relativismo moral induzido pelo olhar psicológico e psicanalítico, e muito menos um adepto das soluções intuitivas para problemas complexos - mesmo que muitos leitores interpretem a ironia e os paradoxos do romance O Homem sem Qualidades nesse sentido. Os ensaios, fragmentos e anotações dos Cadernos/Diários evidenciam, ao contrário, uma imensa preocupação com a dimensão ética das artes e das ciências, dos sentimentos e do entendimento, deixando claro o desgosto do autor com o desleixo e o pensamento mecânico dos poetas.

Musil devolve aos artistas as acusações que esses lançam contra as ciências. ${ }^{17}$ As convenções poéticas não são menos "frias" e "mecânicas" que a rotina do laboratório - mas os poetas e críticos se preocupam menos com a higiene de suas retóricas ocas e com os sentimentos falsos. Contra esse desleixo, Musil pratica uma espécie de autoanálise estética, que obriga o artista a descartar muitas páginas suspeitas de emoções inautênticas. Assim ele exclama em uma anotação dos Cadernos/ Diários: "Como foram poucas as horas nas quais eu senti a intensidade plena! $E$ toda essa plenitude se deu apenas ao preço de um enorme desleixo da reflexão e do entendimento!"18

É muito raro nessa época ver um artista invocar a reflexão e o entendimento como ingredientes indispensáveis para sentimentos e obras de arte verdadeiros. Essa fórmula é especifica de Musil, ela prega a importância da racionalidade (científica) para as emoções, e dela nascem os ensaios que buscam nos métodos matemáticos, na medição e no cálculo a inspiração para depurar e renovar os sentimentos éticos e estéticos. Musil, contudo, não prega a exatidão pela exatidão e lamenta que seu ponto de vista encontra incompreensão tanto entre artistas como entre cientistas: "Quem pensa de modo artístico é hoje ameaçado pelos que não pensam com arte e também pelos artistas que não pensam."19

Ou ele exclama em um fragmento intitulado "Sobre o Ensaio" (em torno de 1914): "A falta de sistemática faz com que os homens escrevam poesia enquanto vivem como porcos. Romantismo pelintra, expressionismo, pendores excêntricos. Conversa de surdos". ${ }^{20}$

O ensaio - no sentido da "tentativa" metódica e do "experimento" reiterado que elucidam um assunto de vários ângulos - se transforma no lastro que sustenta toda a concepção da estética musiliana: é desses ensaios que deveriam renascer novos valores estéticos e éticos - uma vida e uma arte mais sóbrias e dignas da era em que vivemos. A importância dos ensaios para a ficção e a vida do autor está hoje fora de questão; e ela

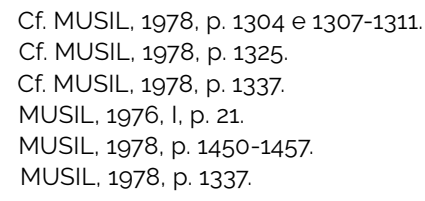


ficou evidente nos anos 1930, quando Musil fez projetos de publicar um conjunto de seus ensaios como complemento e auxilio para a leitura de sua obra ficcional, como lembra Oskar Maurus Fontana:

Musil trabalhou com intensidade na preparação de uma coletânea de ensaios - e esperava do volume considerável repercussão, sobretudo porque os ensaios permitiriam dimensionar melhor a relevância de sua obra literária, dando mais clareza à sua ficção. [...] Ele ficou muito sentido de não poder apresentar essa coletânea ao público. ${ }^{21}$

O desejo do autor foi impedido pela precariedade da existência do autor e de seus editores sob o regime nazista e pelas agruras do exilio e da guerra, e realizou-se apenas postumamente.

\section{A familia e o contexto social contra os quais Musil escreve}

A voz ensaistica de Musil forma um contraponto interessante ao pêndulo estéril entre as posturas polarizadas do seu tempo, que prioriza, de um lado, o amor do conhecimento científico, da tecnologia e da indústria, de outro, enfatiza o apego à sensibilidade da alma, ao patrimônio artístico e a uma longa tradição espiritual. Quanto mais se sentem os efeitos da revolução industrial, mais atraente se torna a fuga para a redoma da arte e da cultura que parece oferecer uma ilha de resistência à fria objetividade do cálculo e um paraiso para os sentimentos (religiosos, misticos, intuitivos).

Na familia de classe média culta na qual Musil nasceu e se criou essa dicotomia típica da época estava presente no contraste entre a mente sóbria e científica do pai e a hipersensibilidade da mãe, sequiosa de distinção espiritual e artística. Apesar da grande expertise do pai e o inegável senso artístico da mãe, havia em ambas posturas um quê de abstração e aquela falta de experiência prática com a realidade política e social que foi uma das sequelas da era do Biedermeier. Essa falha se traduziu em uma certa rigidez mental e em uma falta de generosidade imaginativa que pesaram sobre a criança e contribuiram para as confusões da juventude. Entre as lembranças de infância de Musil encontra-se a menção da xenofobia e dos preconceitos sociais que os pais transmitiram para a criança, por exemplo: "O medo [...] dos russos e dos trabalhadores", uma fobia induzida que "não teve influência posterior" sobre o escritor adulto. Musil considera essa reminiscência infantil digna de análise e reflexão:

É importante ponderar como foi possivel que pessoas boas, como meus pais, suspeitassem de antemão que trabalhadores grevistas e inquietos fossem pessoas más. Quanto prazer e alivio sentiram quando as tropas do exército foram direcionadas para a nossa cidade de Steyr! [...]. Na casa paterna, raramente uma palavra politica. ${ }^{22}$

O olhar analítico de Musil desdobra em reflexão mais ampla a anódina observação da desconfiança da classe média culta, e investiga o fundo dessa desconfiança na qual se misturam as virtudes e os vícios do Biedermeier tardio: o senso legítimo de distinção das pessoas cultas mescla-se com uma docilidade reverenciosa, quase submissa, aos superiores hierárquicos e com um quietismo diante do sistema monárquico que beira a ignorância quase voluntária da realidade social. A tranquilidade paterna expressa a distinção do mérito profissional de quem ascendeu de humildes origens rurais para distinções acadêmicas consideráveis, ocasionando a firme confiança na continuidade da prosperidade material. Na geração dos pais, essa cega confiança ainda parece justificada - afinal, a carreira paterna é coroada pela concessão do título da nobreza de mérito - mas a inexperiência cívica, social e política dessa classe média deixa uma herança dificil para a geração seguinte.

O duplo padrão de valores dessa paradoxal classe média que conjuga critérios generosamente liberais com um conservadorismo surpreendente torna-se patente já na primeira adolescência de Robert Musil. Acostumado com os critérios esclarecidos e liberais da casa paterna, ele descobre no ginásio o exato avesso das

21 FONTANA, O. M. Erinnerungen an Robert Musil. In: DINKLAGE, K. (ed.). Robert Musil: Leben, Werk, Wirkung, Rowohlt, Reinbek bei Hamburg, 1960. p. 335.

22 MUSIL, 1976, V. I, p. 914 
atitudes tolerantes e delicadas: um sistema educativo vetusto, rígido e violento. A tortura que os filhos ai sofriam com a anuência tácitas dos pais, expressa bem a inconsciente subserviência dessa classe aos poderes monárquico, militar e clerical que ditavam as regras ainda segundo padrões autocráticos e quase feudais disfarçados no estilo barroco. Prosperando nesse mundo que concede privilégios aos méritos científicos e tecnológicos, artísticos e culturais, os pais de Musil incarnam as contradições do Biedermeier tardio. O pai fez sua ilustre carreira como engenheiro de máquinas e catedrático nas universidades técnicas mais importantes (Brünn, Steyr, Linz, Klagenfurt); seu apreço pelo conhecimento científico é seguro e seu temperamento equilibrado tolera com tranquilidade as agitações emocionais e as ambições sociais da mãe irrequieta.

É possivel que a rebeldia do jovem Musil contra a mãe (uma mãe que ele amava e com quem manteria até o fim da vida uma profunda conexão afetiva) e a violenta rejeição de suas pretensões culturais, espirituais e sociais represente um verdadeiro retorno do recalcado, dos não ditos políticos e das cegueiras sociais da era Biedermeier, que se fechou e blindou contra os desafios culturais e políticos modernos. Dessa rebeldia nasce a obra ensaística e ficcional de Musil que busca a elaboração intelectual e afetiva da grande crise da modernidade. Os primeiros ensaios de Musil em torno de 1910 abordam as resistências das elites clericais e aristocráticas contra as novas estruturas urbanas, sociais e industriais e o conservadorismo da classe média, e a ignorância generalizada das implicações da revolução das ciências que seguem os principios matemáticos de Newton (em vez de seguir os raros equívocos que também gênios como Goethe cometem - por exemplo, com a teimosa resistência a Newton na Teoria das Cores ${ }^{23}$ ). As efusões do idealismo dos epígonos e diletantes, entretanto, privilegiou os redundantes gestos de avestruz que obliteram a percepção dos problemas prementes e procrastinam as mudanças necessárias das estruturas politicas, sociais e institucionais. ${ }^{24}$

Musil observa, avalia, analisa. Condensa pouco a pouco suas anotações em um lastro reflexivo e crítico da ficção. Suas primeiras obras (Törless e Uniões) apenas parecem focar os sentimentos intimos dos personagens; na verdade, inscrevem esse intimismo em análises perspicazes das relações repressivas entre as classes de idade (mestres e alunos, alunos mais velhos e mais jovens, mais ricos ou mais pobres), entre categorias institucionais (as regras do sistema militar e a mentalidade autoritária do militarismo e da Igreja dominando o ambiente educativo), e das relações entre gêneros. ${ }^{25}$

Os primeiros ensaios de Musil abordam as falhas da longa tradição autocrática através da "mínima moralia" - a elucidação dos aspectos aparentemente menores da educação e da cultura, dos hábitos, convenções e práticas, de símbolos e emblemas. Quando Musil escreve sobre os programas de modernização do catolicismo austriaco ou sobre os ardis da política austríaca, ele revela o enraizamento da política em costumes e práticas cotidianas que formam os tentáculos quase imperceptiveis do poder; analisa como as práticas políticas se impregnam na vida privada e na cultura, padronizando os gestos mais anódinos e inconscientes - por exemplo, o charme cordial e o estilo supostamente barroco da cultura austríaca, que esconde as táticas de cooptação e dominação sob a face risonha de gestos aparentemente generosos, simpáticos e elegantes que devem tornar imperceptivel a exigência rigorosa da contrapartida - a aceitação tácita e submissa das regras do jogo dessa sociedade classista e do status quo de hierarquias anacrônicas.

São padrões culturais e cotidianos, gostos artísticos e literários que impedem, à revelia da consciência e da vontade, uma exploração mais favorável da estupenda revolução científica e industrial e uma transformação mais justa e

\footnotetext{
GOETHE, J. W. von. Sämtliche Werke, 40 vols. Deutscher Klassiker. Verlag: Frankfurt, 1989, Zur Farbenlehre, v. 23.

Cf. os três ensaios: Política na Áustria; Espírito [religioso], Modernismo e Metafísica; e Credo Político de um Jovem (MUSIL, 1978, p. 992-995: 987-992; 1009-1015 respectivamente).

25 Nos diários dos anos 1936 (MUSIL, 1976, I p. 914-915). Musil anota que os personagens Reiting e Beineberg em O Jovem Törless prefiguram "os ditadores de hoje in núcleo".
} 
benéfica da nova realidade urbana que a modernidade de fato já criou, sem que as pesadas estruturas do estado monárquico, os costumes e estilos da vida as absorvessem.

Presos nas armadilhas das antigas estruturas imaginárias, educativas e sociais, até mesmo os intelectuais mais atualizados como $\mathrm{H}$. Bahr, $\mathrm{O}$. Spengler ou W. Rathenau recaem em retóricas e analogias vagas que evidenciam a clivagem (desnecessária, no entender de Musil) entre o pensamento racional e o universo de sensibilidades moles, imprecisas e inautênticas. Musil censura seus colegas artistas de passar ao largo das grandes paixões - e virtudes - do homem moderno: sua obsessão pela medição e o cálculo exatos, pela coleta de dados, por estatísticas e equações matemáticas. Repetindo inúteis lamentos sobre a feiura e a frieza desumana da racionalidade, eles se fecham ao potencial poético fabuloso das ciências e se privam das possibilidades novas que estariam à disposição.

Quando começa seus estudos na Escola Técnica Superior de Brünn (1898-1903), Musil é introduzido aos circulos literários de Brünn, familiarizando-se com o imaginário decadentista, simbolista, nietzschiano-dionisiaco do movimento Jovem Viena (Jung Wien). Pela primeira vez, ele começa a ler Dostoiévski, Nietzsche e Maeterlinck, mantendo, apesar da inesperada e imediata paixão pela literatura, sua "postura distanciada do jovem solitário, que se mantem à parte"..26 Ao mesmo tempo que participa da cena cultural da cidade $^{27}$, ele mantém a distância do observador aberto, mas sempre reservado. A leitura de Crime e Castigo, de Dostoiévski, em junho de 1899 , destaca-se como um acontecimento que provoca "tremenda tontura", um impacto que o autor maduro lembra ainda em 1914 como "experiência de um grande abalo que nunca mais retorna dessa mesma maneira".28 Ele devora as obras de Nietzsche e de Maeterlinck, mas não compartilha o culto nietzschiano-decadentista dos seus amigos artistas. Prefere o misto mais sóbrio de pragmatismo e transcendência que encontra em Emerson, aquele "amigo dos instrumentos mais grandiosos, como cabos oceânicos e logaritmos".29

Musil pensa de modo diferente: pensa com as exigências de exatidão e objetividade do engenheiro e matemático, que espera da poesia mais que sentimentos enfáticos. Ele ainda tem a empáfia juvenil dos estudantes inteligentes e ambiciosos de sua classe, e restos daquela sede de sucesso que Balzac eternizou nos seus heróis paradigmáticos do século XIX: "Entre dezessete e vinte anos - a simpatia imediata com o princípio Gentz. ${ }^{30} \mathrm{O}$ individuo espiritual sem escrúpulos. [...] pertenci de modo periférico aos ditadores de classe."31 - Escreveria Musil mais tarde sobre suas simpatias juvenis pelo diplomata Friedrich von Gentz. Gentz é o modelo do intelectual individualista e autocrático da era Biedermeier - um Rastignac ${ }^{32}$ alemão, transferido para a Áustria de Metternich, onde esse jornalista brilhante usou seus contatos com oportunismo inescrupuloso para galgar altos postos. Ele pouco suspeitava que em breve ia cair na quietude intensa de uma verdadeira visão mística enquanto se considerava imune aos grandes elãs e à moda neomística.

O que sobrou dessas simpatias com o realismo ambicioso na obra de Musil é a compreensão profunda do principio da ação, que o autor ampliará mais tarde com seu conhecimento das

\footnotetext{
26 MUSIL, 1976, v. I, p. 914-915.

O Teatro Municipal de Brünn era mais que um templo da cultura para a classe média abastada, que venerava Goethe, Friedrich Schiller, Friedrich Hebbel e Franz Grillparzer; atendia também a um público operário e intelectual de muito bom nivel, abrindo espaço para os vanguardistas da época (Henrik Ibsen, Gerhart Hauptmann, Arthur Schnitzler, Hermann Bahr e Hugo von Hofmannsthal). Além dos excelentes atores locais (Leo Slezak, Maria Jeritza), contava com grandes grupos e estrelas de Viena e outras capitais, inclusive destaques como Sarah Bernhardt (ver CORINO, 2003, p. 147).

28 MUSIL, 1978, p. 1461.

29 CORINO, 2003, p. 136. Cf. MUSIL, R. Der Mann ohne Eigenschaften. Rowohlt, Reinbek bei Hamburg, 1978, p. 39.

30 Friedrich von Gentz (1764-1832), tradutor de Edmund Burke e simpatizante do liberalismo inglês, começou sua carreira como jornalista em Berlim. Soube aproveitar relações pessoais para ascender rapidamente a um posto de conselheiro imperial na corte austriaca de Francisco I. Trocando sem escrúpulos suas convicções liberais por principios rigidamente hierárquicos, ele se tornaria conselheiro e amigo intimo de Metternich.

31 MUSIL, 1976, p. 914-915, v. I.

32 Eugène de Rastignac é um dos jovens ambiciosos que caracterizam o mundo burguês e a mobilidade social que esse proporciona na obra A Comédia Humana de Honoré de Balzac (R. aparece em Le Père Goriot, 1835, e outros romances).
} 
estratégias de afirmação modernos: a perícia científica e racional, tecnológica e matemática. Mas a ironia musiliana sempre ilumina os aspectos contraditórios - benéficos e maléficos - desses desejos e princípios de ação. O que faz contrapeso ao apreço pela racionalidade e a ação é o vislumbre autêntico da outra árvore da vida e do outro estado que trouxe a notável "experiência valerie" no verão de 1900.

\section{A "Experiência Valerie" e a Outra Realidade Mística (1900-1904)}

O encontro com a jovem Valerie vira do avesso a visão de mundo juvenil de Musil, e assim perde seu brilho também a simpatia frivola com os "ditadores de classe" que enfrentam o mundo com espírito de afirmação autoritária e buscam a proximidade dos homens de poder como Metternich e Bismarck. O breve encontro com Valerie Hilpert, uma moça bela, independente e focada nos desafios atléticos do montanhismo (um tipo feminino novo e exótico na época, que atraiu um séquito de admiradores), parece ter tido o efeito de uma verdadeira transfiguração amorosa, quase de uma experiência de conversão. Musil, então um Dandy altivo, que pensava flertar e galantear com ela, sofre um abalo profundo, que o perturba e leva a fugir:

o destino quis que ela deixasse essa mão repousar por um momento na minha, como que desmaiada, e no próximo instante uma chama ardia dos braços até os joelhos, e dois seres estavam tolhidos pelo raio do amor, ao ponto de quase cairmos pela encosta, onde terminamos por sentar no gramado, abraçados em estado de paixão profunda. Nos separamos nessa tarde, seguida de uma noite insone, uma noite de tempestades interiores, repleta de "tremendas" decisões e, na manhã seguinte, eu já estava longe. Fugi com meu amor da causa e do objeto desse amor, deixando para trás nada além de um aviso que the escreveria [explicando] tudo. ${ }^{33}$

O que absorve as energias de Musil nos dias seguintes já não é mais o objeto amado, Valerie, mas a misteriosa mudança de toda sua disposição afetiva e intelectual. Cessou o domínio dos atos voluntários, direcionados e racionais, o jovem é tomado por um estado de flutuação, uma entrega que o autor mais tarde descreveria como estado aéreo ou gasoso, que o conecta com tudo ao seu redor, intensifica a percepção e abre as sensações os sentimentos e pensamentos em todas as dimensões. Pela primeira vez, ele sente e vive a total presença no seio das coisas e a recíproca presença das coisas no próprio eu:

\begin{abstract}
Não me lembro de ter caminhando saindo pela porta da frente, pois me senti alçado como aqueles fios de aranha outonais que pairam no ar nesse periodo. Deixei-me ser carregado para um lugar qualquer, [...] haviam se dissolvido por completo as fronteiras entre os pensamentos e as referências aos quais esses pertenciam [...]. Tudo era como redomas rosadas, jazendo "no fundo de um mar de ternura e pensamento" ao qual ele pertencia como parte integral. Uma fórmula para esse enigma seria: ele entrara "no coração do mundo".34
\end{abstract}

Na época em que Musil sofre esse abalo mistico-extático, não estava ainda disponível a apresentação sintética do misticismo de Martin Buber, Ekstatische Konfessionen 35 (Confissões Extáticas). Essa compilação de testemunhos muito pessoais de experiências extáticas através dos séculos e das culturas faria sucesso em 1909, influenciando entre outros intelectuais também Walther Rathenau e Walter Benjamin. Esse último, doze anos mais jovem que Musil, provavelmente recebeu dessa Summa do misticismo um impulso para a redação de seu próprio tratado confessional, $A$ Metafísica da Juventude. ${ }^{36}$

É interessante comparar a cautela de Musil com essas manifestações neomisticas focadas de modo unilateral sobre a experiência extática. Igualmente impactado por esse acontecimento que mudou e reorientou sua vida e visão de mundo, Musil se dá o tempo de digerir e elaborar o acontecido. Escreve, sim, aforismos entusiásticos e lânguidos, mas depois descarta essa coleta da inspiração juvenil - o manuscrito hoje perdido

\footnotetext{
33 MUSIL (1900) apud CORINO (2003, p. 159); Corino cita como fonte do fragmento de Musil: KAISER; E.; WILKINS, E. Robert Musil. Eine Einführung in das Werk, Stuttgart, W. Kohlhammer Verlag. 1962.

34 MUSIL apud CORINO, 2003, p. 159.

35 Cf. BUBER, Martin. Ekstatische Konfessionen. Düsseldorf: Gütersloh, 2013.

36 Cf. BENJAMIN, W. Gesammelte Schriften, 12 v., Frankfurt am Main, Suhrkamp, 1980, v. WA 4, II,1, p. 91-104. RATHENAU, Walther. Zur Mechanik des Geistes (Sobre a mecânica do espírito). Berlin: Fischer, 1913.
} 
"Paraphrasen" (Paráfrases ${ }^{37}$ ), uma névoa confusa desses sentimentos, que o autor guardou em uma gaveta depois de ouvir o judicioso conselho de um crítico de Brünn. Essa sobriedade distingue o jovem Musil de autores como Walther Rathenau, e também do jovem Walter Benjamin, que não resistiram à tentação de derramar seus entusiasmos místico-eróticos em tratados um tanto prolixos. ${ }^{38}$

Musil se impõe maior rigor; reelabora e depura sua experiência apenas nos Cadernos/ Diários, atribuindo-a mais tarde (em doses homeopáticas) ao seu herói Törless, que conjuga o inefável místico com os resíduos inefáveis da matemática. Em outras palavras, Musil não vê o mundo da ciência em oposição à experiência mística, mas encontra na matemática - domínio racional por excelência - os mesmos horizontes de maravilhamento e inquietação que sustentam o misticismo espontâneo.

Procura auxilio de diversas abordagens científicas. Compara esse fenômeno com estados psicológicos e busca esclarecimento na literatura, como mostram seus extensos fichamentos de ensaios sobre o romantismo. Suas anotações sobre o ensaio de Ricarda Huch, Blütezeit der Romantik (A Era do Romantismo em Flor), são repletos de perguntas críticas: "até que ponto a concepção mística é legítima; teria esse outro estado afinidades com o inconsciente? Como ele se relaciona com a reflexão crítica e com o desejo físico e sexual?"39 Mas ele chega à conclusão que a especificidade desse estado resiste à teorização da psicanálise - não há na visão mística o bloqueio do recalque que retorna como um sintoma do inconsciente
- mas como um estado sui generis, uma forma aberta e abrangente de sentir e pensar alternativa e complementar ao pensamento racional.

Reconhece que nesse assunto a linguagem psicológica ou psicanalítica mais atrapalha do que ajuda: "A dimensão mística e estética [tornou-se] quase incompreensivel para a contemporaneidade (perda de vocábulos como "alma"); temos que reaprendê-la com os românticos e místicos".40

Sem dúvida o interesse psicológico de Musil nos anos seguintes se deve, em parte, a essa experiência mística. Depois da formação em engenharia, ele faz outro doutorado em psicologia experimental (1904-1908), escrevendo sua tese sobre um assunto epistemológico - a Avaliação das Doutrinas de Ernst Mach, ${ }^{41}$ uma elucidação dos méritos e das falhas ocultas do positivismo antimetafísico do grande físico e pioneiro da teoria da Gestalt. Quanto mais Musil reflete sobre o que the aconteceu naqueles dias de abertura extática inacessivel a vontade e à razão, menos encontra auxílio na psicologia ou nos relatos neomísticos dos contemporâneos! Ele recorre ao suporte do método preciso de descrição que se impõe o mesmo rigor que as ciências exigiriam, mas compensa a rigidez da linguagem conceitual com metáforas novas, mais exatas, cuja sutileza capta os detalhes, os meios, quartos e oitavos tons das mudanças que levam da normalidade para as infinitas variações do "outro estado" extático. Interessante nessas anotações é a honestidade com que Musil registra a diferença entre o autêntico êxtase ("experiência Valerie" serve como sigla para o ser possuido que não depende da

\footnotetext{
37 Uma das reminiscências desse manuscrito perdido é a "Fantasia Paderewski" (MUSIL, 1976, p. 828-831, v. II) - um conjunto de aforismos poéticos que o autor decidiu não publicar. Musil depura seu pathos juvenil, um processo que ocupa as páginas dos diários, onde encontramos versões ensaísticas mais sóbrias e contidas (p. ex., o fragmento "Juizo do sr. R. M. Sobre Si Mesmo" (MUSIL, 1976, p. 815. v. II) ou "Franzensberg" (MUSIL, 1976, p. 820, v. II).

${ }^{38}$ A Metafísica da Juventude é um hibrido entre tratado e confissão, com as sintomáticas redundâncias e vaguezas das reminiscências passionais que Benjamin depurou nas suas obras mais maduras. Musil critica também um ensaio neomistico de W. Rathenau; sua resenha "Observações sobre uma Metapsiquica" (MUSIL, 1978, p. 1015-1020) fustiga a falta de autenticidade que se expressa na teorização de uma experiência que resiste à clareza teórica - um gesto de afirmação intelectual que encontramos em diversos escritos sobre experiências extáticas. Benjamin apresentou a Metafísica da Juventude em 1914 à revista Neue Rundschau, mas Musil (na época redator da revista) o recusou. Nesse texto vibra a influência do mestre Wyneken, o diretor do internato Haubinda, que iniciou Benjamin nas ideias de reforma educacional e nos movimentos de juventude; tem os ecos de amizades e amores poéticos, em ambiguas modulações afetivas que oscilam entre pendores estéticos e amorosos, entre desejo erótico e afirmação intelectual - um estilo confessional que trai as ambições de liderança.

Ver: ROSENFIELD, K. R. Musil e W. Benjamin: duas visões do neomisticimo. In: SOUZA, Ricardo Timm de; BORTOLINI, Bruna de Oliveira RIBEIRO, Helano; MATTOS, Manuela Sampaio de; MESSERSCHMIDT Marcos (org.). Walter Benjamin: barbárie e memória ética. Porto Alegre: Zouk-Capes, 2020, p. 134

39 MUSIL, 1976, p. 137, v. I.

40 MUSIL, 1976, p. 137, v. I.

${ }^{41}$ MUSIL, R. Pour une evaluation des doctrines de Mach. Paris: PUF, 1985.
} 
vontade) e as tentativas de reproduzir esse fenômeno essencialmente efêmero de modo deliberado com esforços poéticos. Dos primeiros anos (entre o verão 1900 e 1904) resultam fragmentos como esse, que constata o valor relativo dessas experiências, que são valiosos justamente como "o outro" dos estados normais:

Certos atos sutis e espirituais são como gotas de um perfume refinado. Têm efeitos intensos, embora durem apenas minutos, horas, dias. No entanto, a duração, o volume de uma sensação, têm, sim, seu valor próprio (devo admiti-lo de mal grado) - muito embora costumemos negligenciar este fato. Não há nada à fazer: nossa vida dura um tempo determinado, e cada hora abre-se como um buraco hiante, filho da morte, que devemos preencher. E aquelas coisas sutis não prestam para preencher coisa alguma. A sutileza, os atos espirituais são dons, dádivas, "abstratos" da vida, que não tem dimensão psíquica. Eis por que não preenchem as horas. Para poder fazê-lo, eles precisam antes transformar-se em vida e o critério é: para qual estado ético eles nos transportam e quanto tempo conseguem agir sobre nós. Embora possam permanecer moralmente relevantes, eles empalidecem eticamente. Eles descrevem círculos na alma e o fator "volume" depende da amplidão destes círculos, da duração do movimento, das horas nas quais nós somos ainda éticos

Uma outra espécie é a dos grandes Amantes, Cristo, Buddha, Goethe... eu, nos dias de outono em que amava Valerie. ${ }^{42}$

Esse rigor que renuncia aos exageros entusiásticos confere sua grande qualidade aos ensaios musilianos e um potencial reflexivo próximo dos grandes moralistas como Pascal, Montaigne ou Montesquieu. Posteriormente o autor se debruça sobe livros eruditos sobre o misticismo do teólogo e historiador da religião, Adolf Harnack e do psicólogo e filósofo Ludwig Klages. ${ }^{43}$ Mas sempre se lembra que precisa pensar como artista, transformar o conhecimento em algo que tenha a dupla qualidade estética e ética. É dessa reflexão que emergem aos poucos as noções tipicamente musilianas do "racioide e do não racioide" - uma dicotomia que distingue o estado normal (racional) e o extático-poético, nos ensaios dos anos 1910-1920.44 Ela está presente na concepção de quase todas as grandes novelas (Uniões, O Melro, Três Mulheres) e na dimensão utópica do romance $\mathrm{O}$ Homem sem qualidades que dedica um capítulo às "duas árvores da vida"45 e à "exigência de um secretariado-geral da exatidão e da alma" - uma representada pela paixão humana pelo conhecimento, a ciência e as técnicas, a outra pela entrega igualmente passional a sentimentos dificeis de definir.

\section{O rigor crítico do ensaísta}

A cuidadosa elaboração narrativa posterior dessa experiência mostra o impacto duradouro desse "outro estado" sobre o pensamento do autor, que sempre de novo abre espaço aos insights místicos, porém mantendo-as como faíscas efêmeras que apenas cintilam aqui e ali nas suas reflexões e na obra ficcional. Musil suprimiu a resposta poética impulsiva e prefere falar de um método novo, e dos benefícios que a precisão das ciências traria para o artista contemporâneo, ele pensa também na necessária renovação da sensibilidade contemporânea - um senso estético que no fundo sabe da importância dos conhecimentos e teorias modernas, embora continue brincando com formas ultrapassadas. Para renovar as formas literárias, Musil exige que o escritor lance mão das técnicas de observação dos cientistas - por exemplo, dando-se o trabalho de escolher e ordenar séries de observações e fazendo amplas coletas de dados. Transpor o rigor científico para a poesia significa não ceder aos primeiros impulsos entusiásticos, não deixar os elãs momentâneos se derramarem em poesia de ocasião ou em imitações das belezas de Goethe ou de outros modelos.

A reflexão madura e a capacidade de despojar a experiência meramente subjetiva tanto do entusiasmo extático, como da tentativa de teorização, faz de Musil um dos primeiros críticos a apreciar a corajosa renúncia a todos os falsos

42 Cf. MUSIL, 1976, p. 821, v. II.

43 Cf. as fichas de leitura à respeito de Harnack (Der Eros in der Alten christlichen Literatur) e de Ludwig Klages (Vom kosmogonischen Eros, Eugen Dietrichs, 1929) (MUSIL, 1976, p. 325. v. II; e MUSIL, 1976, p. 616, v. I, respectivamente).

44 Cf. o ensaio Esboço sobre o modo de conhecimento do poeta (MUSIL, 1978, p. 1025-1030).

45 Eis o título do capítulo 116 da segunda parte de $O$ Homem sem qualidades: "As duas árvores da vida e a exigência de um secretariado-geral da exatidão e da alma" (MUSIL, 1978, p. 415-428). 
elãs que distingue as narrativas de Kafka e Walser. A "Crônica literária" de $1914^{46}$ homenageia a combinação de sobriedade e delicadeza desses dois artistas, e permite a Musil refletir sobre seu próprio programa estético.

Inicia com considerações sobre o gênero novela que se distingue das feições mais objetivas e racionais do romance pelo foco em uma experiência de abalo cuja expressão desafia a forma do enredo racional e resiste à linguagem clara e distinta. ${ }^{47}$ É essa última coragem lúdica e poética de dar a justa importância às pequenas coisas sem importância aparente e às tutameias aparentemente triviais que Musil admira nas obras de Kafka e Walser. Nas esquisitices dessa sóbria pequena prosa Musil encontra a arte de acessar os misteriosos abalos da alma e a medida exata dos pequenos sentimentos importantes - um antídoto bem-vindo ao idealismo sentimental.

Musil encontrou na arte de Kafka e Walser a mística pura e despojada dos pendores excessivos do neomisticismo dos círculos literários em torno de figuras como Klages, George ou o reformista educacional Wyneken, que nesse ano que precede a Primeira Guerra Mundial ainda exerceram grande influência intelectual - entre muitos outros também sobre o jovem Benjamin. ${ }^{48}$

A reflexão sobre as afinidades com esses jovens artistas é uma das múltiplas etapas nos "ensaios" musilianos dessa época de ver com mais clareza seus objetivos como artista e toda sua concepção estética, além de compreender melhor seu próprio modo tão diverso e peculiar de sentir, pensar e escrever literatura. O ensaio "O Homem matemático", a ficção (auto)crítica "Sobre os livros de Robert Musil" ou o fragmento "Sobre o Ensaio"49 dos anos 1913-1914 começam a delinear o programa estético musiliano na dupla perspectiva do matemático (que se distancia da Cultura-fetiche e do culto da arte) e do poeta em busca de formas mais adequadas e autênticas para sentimentos profundos que desafiam a linguagem.

O fetiche da Kultur - da Cultura germânica quase sacralizada desde o seu tardio apogeu com o classicismo de Weimar e o idealismo alemão - serviu por mais de um século como compensação para a exclusão da política e do governo. Musil cobre de escárnio os "emuladores de Goethe e Rembrandt5o" à espera de guias e grandes homens que reconduzirão a nação de volta pra esse lugar pristino do espírito, que os poetas e intelectuais teriam de proteger de interferências práticas e políticas, como se a alma e o espírito se movessem numa esfera além da política e dos problemas sociais e econômicos ${ }^{51}$. Musil critica a versão austríaca desse exacerbado idealismo germânico - o mito da cultura barroca - que apenas modulou esse culto com algumas reverências às próprias tradições musicais e teatrais supostamente mais antigas. Musil "tinha uma visão impiedosa do patrimônio literário austriaco e alemão. Sabia onde estavam seus picos altos", mas também "quanta trivialidade estava sendo servida em nome de reverências nacionais".52

Poucos autores foram tão conscientes quanto Musil da carência peculiar da cultura germânica. É raro encontrar um escritor que sinta o pesar de ter que escrever em uma cultura sem a grande tradição filosófica-e-literária da Europa Ocidental. Musil diz que a Alemanha que teve com Nietzsche seu primeiro espírito livre e quase o único tênue elo com os notáveis ensaios morais

\footnotetext{
46 Musil aborda as novelas de Kafka e Walser como um desafio para a renovação dos padrões estéticos modernos (MUSIL, 1978, $\mathrm{p}$ 1465-1469).

47 Cf. o capítulo 32 do primeiro livro de O Homem Sem Qualidades (MUSIL, 1978, p. 89-92).

48 Com o mesmo senso crítico, Musil rejeitaria mais tarde também o manuscrito que Benjamin apresentou em 1914 à revista Neue Rundschau, pois a Metafísica da Juventude não passa de uma confissão dos elãs juvenis mais íntimos - sentimos nela a admiração pelo mestre Gustav Wyneken, o diretor do internato Haubinda, que iniciou Benjamin nas ideias de reforma educacional e nos movimentos de juventude; tem os ecos de amizades e amores poéticos, em ambiguas modulações afetivas que oscilam entre pendores estéticos e amorosos, entre desejo erótico e afirmação intelectual - um estilo confessional que trai as ambições de liderança.

49 Der mathematische Mensch (April-Juni 1913); (MUSIL, 1978, p. 1004-1008); Über Robert Musil's Bücher (Januar 1913); (MUSIL, 1978, p. 995-1002); Über den Essay (MUSIL, 1978, p. 1334-1337).

${ }_{50}$ Os termos em alemão são Goethemenschen, Rembrandtdeutsche; cf. MUSIL, 1976, p. 380, 443, 657, v. I; MUSIL, 1976, p. 469, 470, v. II. 51 Esse apego à pureza espiritual da cultura germânica, encontramos ainda nas Considerações de um homem apolitico de Thomas Mann Ver: MANN, Th. Betrachtungen eines Unpolitischen. Berlin: Insel Verlag, 1922 [1918]. Cf., em particular, o capitulo Der Zivilisationsliterat, p. 44-73. 52 MUSIL, Robert. Precision and Soul. Essays and Addresses (Burton Pike and David S. Luft, eds. and transl.). University of Chicago Press, 1990. p. XIX.
} 
e filosóficos que iniciaram na Inglaterra no século XVI e na França no XVII53. Musil sente falta do lastro intelectual, ético e estético que essas culturas receberam dos ensaios de Thomas Morus, Francis Bacon e Hume, de Michel de Montaigne e Montesquieu. Essas reflexões liberaram o pensamento filosófico e a sensibilidade dos leitores da abstração dogmática da escolástica e confrontaram o público culto com os desafios e as mudanças de sua era. A experiência desses homens no "mundo" entrelaça a vida intima com as informações científicas e as descobertas de novos continentes e culturas, filtrando os acontecimentos políticos e as mudanças dos costumes na trama da sensibilidade pessoal. A dupla abertura ao mundo e aos próprios sentimentos, a honestidade e a franqueza das ponderações que criou a invejável forma dos Ensaios que Musil estima superior à objetividade abstrata de muitos tratados sistemáticos. A educação do espírito livre no público austríaco e alemão, em contrapartida, é muito recente: começa apenas com Goethe e Nietzsche. Mas esses preciosos modelos que ensinam a flexibilizar o intelecto e os afetos esbarram muitas vezes na rigidez mental dos "emuladores de Goethe" e dos "alemães do tipo Rembrandt", presos nos mecanismos mentais de ensaístas diletantes como Paul de Lagarde e Julius Langbehn ${ }^{54}$, que prepararam esse idealismo oco e o culto da arte que o nazismo iria absorver na sua propaganda. ${ }^{55}$

Esse rígido imaginário com seus pendores de retornar aos padrões tradicionais do classicismo ou da idade média encontra-se também nas múltiplas resistências austriacas contra a modernidade. Elas se expressavam ora pelo apego ao barroco, ora na rivalidade com o sucesso econômico e militar "prussiano", denigrado como o frio espírito calculista do negócio. Também nesse ponto Musil contraria seus compatriotas, assinalando que a Alemanha soube pelo menos criar rudimentos de estruturas liberais e iniciativas culturais um pouco mais concretas - por exemplo, o mecenato cultural que, na Alemanha, financiava artistas, ao passo que na barroca Áustria tudo continuava como antigamente, na dependência das boas graças da Casa Imperial. De ensaio em ensaio transparece o escárnio que Musil reserva às atitudes antimodernas que se dão o luxo de desprezar inclusive os aspectos altamente positivos do liberalismo da Europa Ocidental, acusado na perspectiva da Europa Central de provocar a decadência espiritual das civilizações mais desenvolvidas e refinadas como a França e a Inglaterra.

Musil detecta nesse culto exaltado a fixação nos hábitos apolíticos do Biedermeier que manteve a classe média sob tutela, desviando seus desejos e afetos para as belas artes. A inflação espiritual e sentimental dessa veneração da cultura distorceu a visão dos méritos das ciências, da matemática e da tecnologia moderna, impedindo que a cumulação de conhecimentos e técnicas se traduzissem em experiências criativas no mundo da classe média culta. O ensaio busca soluções parciais para esse mal-estar, criando degradés entre os âmbitos da alma e da razão que permaneceram opostos na cultura alemã.

Para Musil as considerações culturais e artísticas sempre levam a considerações políticas e sociais. A cultura científica da primeira modernidade (renascentista), por exemplo, nasce tanto do rigor escolástico, como do espírito liberal dos amantes de liberdades filosóficas e literárias que criaram a grande tradição do gênero ensaio de pensadores como Montaigne. Seu estilo de reflexão leva Musil a anotar no seu diário: "entre outras coisas, foram considerações racionais que me fizeram simpatizar com o socialismo"56 - uma observação que ele elabora no ensaio Credo Político de um Jovem (Politisches Bekenntnis eines jungen Mannes). Em uma rápida sintese de história da Ciência, Musil evidencia que o desenvolvimento social e democrático é uma necessidade inscrita na estrutura coletiva

\footnotetext{
53 Cf. o elogio ao rigor da fantasia ensaística de Nietzsche (MUSIL, 1976. V. I, p. 939,): "n. 105; citação de Nietzsche: na verdade, a fantasia dos bons artistas ou pensadores produz sempre coisas boas, médias e ruins; mas seu juizo, agudo e treinado, rejeita, seleciona...".

54 Fritz Stern dedica à análise do ensaismo diletante desses dois autores seu livro The Politics of Cutural Despair: a study in the Rise of the Germanic Ideology (Berkeley, University of California Press, 1974)

55 Cf. MICHAUD, Eric. The Cult of Art in Naz Germany. Berkeley: Stanford University Press, 2004.

56 MUSIL, 1976, p. 914-915, v. I.
} 
do conhecimento científico. O jovem engenheiro, à vontade no mundo das turbinas e das pesquisas aerodinâmicas, ${ }^{57}$ registra o descompasso que separa a audácia do intelecto do conservadorismo das emoções cegas para a poesia das ciências, que transformaram em realidade os sonhos miticos mais antigos da humanidade.

Nas mãos de Musil, o ensaio retorna ao formato exigente do gênero, tal como definido por Montaigne: "ensaio" no sentido literal, como tentativa, esforço, experimento para abrir novos caminhos reflexivos para além das certezas tradicionais e como antídoto às confusões vagas da intuição. Antes e depois da Primeira Guerra Mundial, Musil criticou as raízes ocultas de um mal-estar que a maioria percebeu apenas nos seus sintomas. Seu insight lúcido

mostrou a catástrofe eclodindo dos fatos culturais e políticos, muito antes de esses sintomas se tornarem manifestos para o sensório mais rude dos seus contemporâneos. Ele os registrou quando estavam ainda observáveis, isto é, no momento de sua eclosão. ${ }^{58}$

Mostrar e analisar a eclosão imperceptivel de uma catástrofe requer não apenas senso de observação, mas também método. Musil é incansável na coleta de dados, faz listas dos assuntos a serem investigados (categorias sociais e as relações entre elas, tipos de formação, instituições e associações, competências do estado e da Igreja, relações entre gêneros, etc.) e faz jogos de permutação com esses dados que testam as relações que poderiam se tecer entre os elementos observados. Mais tarde, quando o grande romance já está na fase de acabamento, Musil explicaria em uma entrevista de 1926 que seu objetivo não foi escrever um romance histórico sobre a sociedade um ano antes da Primeira Guerra Mundial: "O que me interessa são as conexões que captam o que é característico no plano da mentalidade espiritual e intelectual - quase diria: capto o aspecto fantasmático e espectral do acontecimento".59 Em outras palavras, ele procura captar as estruturas imaginárias profundas, oferecendo uma análise social e simbólica, política e ética que revele os mecanismos inconscientes, os gestos simbólicos que direcionam o comportamento à revelia da consciência - aquilo que Bourdieu chamaria, décadas mais tarde, de "habitus". ${ }^{\circ}$

\section{Considerações finais}

A abordagem da complexidade cultural e científica, social e política - começando pelo o contexto familiar no qual Musil nasceu e a sociedade autoritária para e contra a qual ele escreve - elucidou o sentido musiliano das metáforas matemáticas no âmbito dos sentimentos, da alma e do espírito e tornou plausivel as razões pelas quais é preciso transpor os métodos e o rigor científicos para o domínio da arte. O uso e a observação rigorosos da linguagem são para o autor as armas do poeta contra a hipocrisia dos hábitos e dos sentimentos que ocultam em gestos e formulações imprecisas interesses escusos e deslizes morais muitas vezes legitimados em nome de emoções vagas (místicas, patrióticas, amorosas ou estéticas). A atitude sóbria e rigorosa do autor a respeito de sua própria experiência místico-erótica exemplificou o sentido da metáfora inicial "estados de agregação da moral", e elucidou uma etapa crucial na trajetória do artista Musil e da transformação do jovem engenheiro racionalista em "moralista" e romancista importante, cujos ensaios recriam, no século XX, a reflexão profunda dos grandes ensaistas como Montaigne ou Hume.

\section{Referências}

BALZAC, Honoré de. A Comédia Humana. O Pai Goriot. Porto Alegre: L\&PM, 1998.

7 MUSIL, 1976, p. 948, v. I.

58 Cf. o jornalista suiço Armin Kesser, apud CORINO, 2003, p. 1449

59 MUSIL, 1978, p. 939

Pierre Bourdieu expõe esse conceito na obra La Distinction (Die feinen Unterschiede. Kritik der gesellschaftlichen Urteilskraft. p. 274 Suhrkamp, Frankfurt am Main, 1982). O habitus compartilhado tem o efeito inconscience de padronização dos comportamentos e gestos no interior de grupos sociais homogêneos, que assim se distinguem uns dos outros: "O hábitus tem como efeito que o conjunto das formas de prática de um agente (ou grupo de agentes em situações sociais similares), como produto da aplicação de esquemas idênticos (ou mutuamente intercambiáveis), sejam ao mesmo tempo de caráter sistemático e sistematicamente diferenciados das formas de prática constitutiva de outro estilo de vida." 
BENJAMIN, Walter. Metaphysik der Jugend (Metafísica da Juventude). In: WALTER. Gesammelte Schriften. Frankfurt am Main: Suhrkamp, 1980. 12 V.

BOURDIEU, Pierre. Die feinen Unterschiede. Kritik der gesellschaftlichen Urteilskraft, Frankfurt am Main: Suhrkamp, 1982.

BUBER, Martin. Ekstatische Konfessionen. Düsseldorf, Gütersloh, 2013. https://doi.org/10.14315/9783641248512

CANETTI, E. Jogo dos Olhos. São Paulo: Companhia das Letras, 2010

CORINO, Karl. Robert Musil. Eine Biographie. Reinbek bei Hamburg: Rowohlt, 2003.

FONTANA, O. M. Erinnerungen an Robert Musil. In: DINKLAGE, K. (ed.). Robert Musil: Leben, Werk, Wirkung. Rowohlt, Reinbek bei Hamburg, 1960.

GOETHE, J. W. von. Sämtliche Werke. 40 v. Deutscher Klassiker Verlag: Frankfurt, 1989. (Zur Farbenlehre, v. 23).

HARNACK, Adolf von. Der Eros in der Alten christlichen Literatur. Berlin: De Gruyter, 1918.

KAISER; E.; WILKINS, E. Robert Musil. Eine Einführung in das Werk. Stuttgart: W. Kohlhammer Verlag, 1962.

KLAGES, Ludwig. Vom kosmogonischen Eros. Munich: Eugen Diederichs, 1929.

MACH, Ernst. Die Analyse der Empfindungen. Jena, G. Fischer, 1902.

MANN, Thomas. Contra a concepção engajada, política da literatura de seu irmão Heinrich: Betrachtungen eines Unpolitischen, Berlin, Insel Verlag, 1922 [1918].

MANN, Thomas. Betrachtungen eines Unpolitischen, Berlin, Insel Verlag, 1922 [1918].

MICHAUD, Eric. The Cult of Art in Naz Germany. Stanford University Press, 2004.

MUSIL, Robert. Pour une evaluation des doctrines de Mach. Paris: PUF, 1985

MUSIL, Robert. Precision and Soul. Essays and Addresses. Eds. and transl.: Burton Pike and David S. Luft. University of Chicago Press, 1990.

MUSIL, Robert. Robert Musil. Eine Biographie. Reinbek bei Hamburg: Rowohlt, 2003.

MUSIL, Robert. Kleine Prosa und Schriften. Rowohlt: Reinbeck bei Hamburg, 1978.

MUSIL, Robert. Tagebücher, 2 vols. Reinbek bei Hamburg: Rowohlt, 1976 (TB I and TB II). Ed. Adolf Frise.

MUSIL, Robert. Der Mann ohne Eigenschaften. Rowohlt: Reinbeck bei Hamburg, 1976 (MoE).

MUSIL, Robert. O Homem sem qualidades. Trad. Lya Luft e Carlos Abbenseth. Rio de Janeiro, 1989.

MUSIL, Robert. O Homem sem qualidades. Trad. João Barrento. Lisboa: Dom Quixote, 2008.
MUSIL, Robert. O Jovem Törless. Trad. Lya Luft. Rio de Janeiro: Rio Gráfica, 1986.

MUSIL, Robert. Uniões. Trad. Kathrin Rosenfield e Lawrence Flores Pereira. São Paulo: Perspectiva, 2018

MUSIL, Robert. Ensaios I. Introdução, notas e tradução de K. Rosenfield. São Paulo: Perspectiva, 2020. [No prelo]

RATHENAU, Walther. Zur Mechanik des Geistes. Berlin: Fischer, 1913

ROSENFIELD, K. R. Musil e W. Benjamin: uma amizade perdida e duas visões do neomisticimo. In: TIMM DE SOUZA, Ricardo et al. (org.). Walter Benjamin: barbárie e memória ética. Porto Alegre: Zouk, 2020. [No prelo]

ROSENFIELD, Kathrin. A Época de Musil em Verbetes In: MUSIL, Robert. Ensaios I. São Paulo: Perspectiva, 2020. [No prelo].

STERN, Fritz. The Politics of Cutural Despair: a study in the Rise of the Germanic Ideology. Berkeley: University of Californi Press, 1974.

WILKINS, E. Musil's "Affair of the Major's Wife" with an Unpublished Text. The Modern Language Review, v. 63 , n. 1, p. 74-93. https://doi.org/10.2307/3722647

WOLF, Norbert Christian; NÜBEL, Birgit. Robert-Musil-Handbuch. Berlin: De Gruyter, 2016.

WOLF, Christian. Kakanien als Gesellschaftskonstruktion, Robert Musils Sozioanalyse des 20. Jahrhunderts. Viena: Böhlau, 2012. https://doi.org/10.26530/ OAPEN_437166

\section{Kathrin Rosenfield}

Professora titular de Filosofia e Literatura na Universidade Federal do Rio Grande do Sul (UFRGS) em Porto Alegre, RS, Brasil.

\section{Endereço para correspondência}

Kathrin Rosenfield

Rua Bororó, 583

Porto Alegre, RS, Brasil

91900540 